\title{
"Coulda Nietzsche Shoulda"
}

\author{
Robert Guay ${ }^{1}$
}

Abstract

This paper argues that Richardson's interpretation of Nietəsche's account of evaluative privilege doesn't work, and that the project that depends on it fails.

\section{Introduction}

This seems like a good occasion to say how much I admire John Richardson's writing. Whether he's writing about the metaphysics of becoming, social selection, or even the Ereignis, I always profit and learn from engagement with his work. This profit, furthermore, stems from the clarity and thoughtfulness of the writing. Sometimes I, at any rate, learn from the texts that create muddles and beg questions, but Richardson's writing is deeply considerate of philosophical texts and issues. And I am grateful for this opportunity to mention that.

Here, however, I want to argue that a central element of his account in Nietzsche's Values doesn't make sense. ${ }^{i}$ What I mean thus to offer is a philosophical analysis rather than a textual one. I don't want to generate a contest of close readings in which I cite passages to show that Nietzsche really thought something different from what Richardson attributes to him on this or that point. What I want to do, rather, is show that a philosophical reconstruction of Richardson's interpretation of Nietzsche's account of what might be called evaluative privilege doesn't work, and that the project that depends on it fails. My approach of course leaves open the possibility that Richardson's interpretation is completely accurate and Nietzsche's position simply makes no sense. This would be an unfortunate place to end up, however. After all, what is at stake here is not the details of passages; as Richardson says, Nietzsche sometimes "drifts" (12) and "slips" (30) in his writings. As often in trying to understand Nietzsche, locating a general approach to philosophy or a "dominant project" (30) is the central matter.

\footnotetext{
${ }^{1}$ Robert Guay, Binghamton University, United States. E-mail: rguay@binghamton.edu.

Robert Guay is Associate Professor of Philosophy at Binghamton University. He is the editor of Dostoyevsky's Crime and Punishment: Philosophical Perspectives (Oxford University Press, 2019) and the author of Nietzsche's On the Genealogy of Morality: A Critical Introduction and Guide (Edinburgh Critical Guides to Nietzsche) (Edinburgh University Press, 2022). He is also the author of a number of articles in The Journal of Nietzsche Studies and The European Journal of Philosophy.
} 


\section{2 "Coulda Nietzsche Shoulda"}

\section{The problematic}

Richardson's account in Nietzsche's Values is deep and complex, but it is worth calling attention to a few key elements. On Richardson's account, Nietzsche is offering a naturalistic account of what values are. Values, treated in a "quasi-scientific spirit" (2) are mere "valueds" that play a key signposting role in behavior; they signal the targets that life is aiming at in its pursuit of power. Nietzsche not only takes this naturalistic stance towards what values are, but also insists that the results of his inquiry should inform how we value. Once we see that values are nothing outside of life's striving for power, we ought to reevaluate our values. Recognition of what valuing is should change both "its force and its content" (26) so that we come to adopt a perspectival attitude toward our own valuing, and in so doing shift what we value to better align with our meta-evaluative valuation of truth and power.

A main challenge of Nietzsche's account, on this reading-apart from getting the psychology right-is explaining how some values can be better than others. From a naturalistic perspective, there are only facts about what is valued, but Nietzsche wants to leave room to insist that "real values are the things that should be valued" (252). He wants this, of course, in order to claim that his own favored values are superior and should be adopted by others. This is not just a bit of egoism, but integral to his position. The demand to recognize the truth of valuing, and adopt values accordingly, relies on some claim of privilege to back it up.

So what is the nature of this evaluative privilege? Richardson characterizes it in a number of ways; I take them to collective contribute to a full picture. Here are some of the characterizations, with some emphasis added:

- "How Nietzsche can justify his values to us" (29; cf. 26, 61)

- Nietzsche can "give reasons for his values" (12; cf. 26)

- These are reasons "both for him to hold them and for some others to hold them as well" (12)

- These reasons convey "a special status, make [the values] good" (26)

- The values have a distinctive "authority" (53; cf. 63)

- Nietzsche has a "ground" for his evaluative stance (241)

- Nietzsche's favored values "should be valued" (252; cf. 33, 76, 161)

Some values are better than others. There is a rational ground for the superiority of values. The rational ground justifies these values, both in the sense of furnishing reasons for acceptance and in the sense of conveying an authoritative status to these values. As a result, Nietzsche's favored values should be valued by himself and others; he is not merely entitled to hold them, but is in some sense right to do so. This is a fairly robust sense of privilege, then. Contrast, for example, the sense in which one has a reason to $\phi$ whenever one has an urge to do so-say, to eat a pot of glue, for example. One has a reason to eat that glue (because it would satisfy that urge), and perhaps we can even say it would be justified, but it is not good to eat the glue, the value of eating the glue has no special authority, and it would be especially hard to say that the reason is persuasive or that anyone should eat the glue or value eating the glue. Nietzsche, by contrast, needs to account for how it could be that we (some of us, at least) really should adopt his favored values. 
We can focus this a little by imagining an example. The particular example does not matter so much, since Nietzsche grounds his account in values "he claims we all share" (29), power and truth; change any details of the example that you like. But imagine someonecall him Saul. Saul values many things. Some of his values he sees as idiosyncratic preferences; some he realizes are stable for now but are more or less mutable; and still others are deeply tied up with his sense of self-indeed, he hardly sees them as "values" at all, or even considers them as separate from who he is. We can observe at least some of the values in features of his life: he drives a Prius, tinkers with his pedal board, actively worries about being a good enough parent, votes only in presidential years, occasionally takes extraordinarily long lunches, gives to United Way, whatever. The question that I want to pose is: why should Saul revise his values, possibly radically? And does Nietzsche give him a compelling reason to do so? Should he be persuaded? By what authority should Saul switch and recognize that different values would be better? Are his current values unjustified in relation to the privileged standing of Nietzsche's favored ones? Or if Saul insists on retaining his values, is there a way to avoid the "perspectival stand-off" (260) this produces?

Richardson of course offers an account of how some values can be privileged. We can add some complications later, but here is the simplest rubric of it: "You should value V because $\mathrm{X}$ values V" (63). And "X" needs to be located "in us" (65) to avoid the "externalist" position. Nietzsche, that is, is not claiming that there are values that obtain independent of any human valuing, that somehow stand over us and exert authority on us from outside. He must then be claiming, with regard to his favored values, that we already do, in some sense or with respect to some part of us, value them, and value them in a way that marks out their superiority. Values are only valuable, as it were, when someone values them, and so we do, and so Saul does, and so everyone does. We should value $\mathrm{V}$ because there is some important way in which we already do.

\section{A quick aside}

What should come now is a detailed analysis of this account. That will come next, but first I wanted to mention an issue that is not my main topic, but intersects with it. According to the naturalistic account, "there's really no subject or agent" (162). The self is merely a bundle of drives; agency is a misguided self-interpretation of a particular drive. A naturalistic psychology is accordingly a "psychology of drives not agents" (81) and "life is what values" (46). The question I have now is: what sense does it make to say that someone should value $\mathrm{V}$ if there are no subjects or agents? Who should value V? Normally, I think, if you tell someone that they should $\phi$, then there is a reason for them to $\phi$. But here the 'should' claim seems to instead suggest: you don't really exist, but this consideration is compelling from some other standpoint that you might adopt, perhaps that of one of your drives, if you were to think of yourself otherwise. It is hard to see how Saul's standpoint, for example, is to be addressed, how he might be persuaded or given reasons, or how a revaluation might be justified to him. And then it is hard to see how it could make sense to say that Saul should value V. But let's set this aside.

\section{Some possibilities}

The basic form of the strategy for accounting for evaluative privilege is to appeal to values that one already has in privileging ones that may or may not be recognized as more 


\section{4 "Coulda Nietzsche Shoulda"}

valuable. We can consider this more carefully by looking at some of the specific strategies for distinguishing the better values. These are the specific strategies that I'll discuss: (a) we already value the privileged values, (b) we value the privileged values 'deep down', (c) our meta-values favor the privileged values, (d) we would be better off with the privileged values, (e) if we adopt the privileged values, then we will come to recognize their superiority, (f) a part of us already wants the privileged values, (g) we implicitly prefer the privileged values, and (h) we should adopt the privileged values for the sake of consistency. Some of the strategies fit well together; they often appear in bunches. It will nevertheless be easier to consider them individually. I do not think there is any disadvantage in doing so. Even if they are meant to be taken together, or even if some of them do not belong here at all, disentangling them will still allow us to see how helpful each might be. My view is that they are not helpful, either singly or in combination.

a) Already value them.

Nietzsche's appeal on behalf of his favored values, Richardson writes, "is to the authority of the values already in us" (66). The favored values are privileged because we already value them. There are two possibilities here. One is that we do already, in some sense, value the privileged values. The problem with this is that we also, in obvious senses, don't value them; otherwise discussing their revaluation would be beside the point. Saul, for example, might already value vaping, tribal tattoos, bias-cut skirts, and backcountry camping, but he also does not, as we could see in his attestations and other behaviors. We wouldn't say that he should value them (more or differently) because he already does in whatever residual way that he does. What I think Richardson has in mind, however - the other possibility - is that we already have some values that somehow support and convey authority to the privileged ones. But this has just the same problem as the other possibility. Saul, presumably, already has the authority-conveying values, and nevertheless lacks the privileged ones. He is content with what he values and how. He has no reason to newly favor some values over others, or adopt different ones; if he has any authority-conveying values, they're already implicated in the whole set of values he holds. So the appeal to what he already values can at most be a minimum requirement for internalism and it must depend on some other consideration-perhaps one of the ones below.

b) Deep down.

Another way of thinking about privileged values might be that we should favor the values that stem from the "deepest" sources within us. Richardson thus writes of a "deeper self" (69), "deepest values" (51), "what we deeply want" (70), and the not-at-all-funny "endsetting bottom of each of us" (69). "Depth" strikes me as an interesting category, worthy of investigation. But depth does not produce a reason for valuing: there can be deep drives and values that we want to get rid of. Saul suffers from trypophobia, which stem from the very root of his animal nature, but that does not imply that he should disvalue lotus pods; he also has some deep self-destructive urges that he would rather not have. Perhaps the superlative "deepest" can do some work here that "deep" cannot, but it's not clear why it would coincide with value.

c) Meta-values. 
Another promising strategy is to appeal to "meta-values," that is, "values with the secondorder role of steering one's (first-order) valuing" (27). Saul should value V, on this account, because he values truth and power, which shape his other values, and truth and power explain the privilege accorded to V. But there is no reason why Saul should take metavalues as such as more compelling. After all, Saul reflects, he has meta-values toward his appetites based on his desire to be model-thin, and a meta-value of being ruthlessly devoid of human feeling so that he might better advance his career in administration, but he is glad that he accords those meta-values relatively little weight and they have little effect on his first-order values. (Some of his meta-values, by contrast, he wishes were a bit stronger: e.g., the values he sets on his regard for stable friendships and on not being addicted to crack.) Perhaps what Richardson is calling attention to is not meta-values per se, of which we all have lots, but meta-values that shape "all our particular human values" (163, emphasis added; cf. 28). Saul's meta-value of wanting to enjoy Game of Thrones more has only a very narrow application; his meta-values of truth and power, by contrast, are much more general. But why should Saul prioritize his more general values? Just because they are more general? To him they don't seem to be most important or urgent, or even particularly interesting.

d) Hypothetical eudaimonism.

By “eudaimonism" here I don't mean happiness, specifically, but an appeal to the ultimate good of the agent. "Hypothetical" indicates that the relevant appeal is to what the agent would find valuable, were they to see things differently, for example if they adopted a "clearheaded egoism" (109). I think Richardson intends this to explain the notion of well-being rather than the notion of what someone should value, but perhaps it can serve either purpose: "Very roughly, P's good is what his or her values would be if corrected with respect to power and/or truth" (12). The trouble with this as a way of explaining evaluative privilege is that we have no reason to judge things from the hypothetical viewpoint. If you tell Saul that he should adopt these values because they would contribute to his good if he had different values, then you haven't told him anything. "Corrected" doesn't add anything here either, since that is a way of characterizing what is up for explanation.

e) Prospective eudaimonism.

This strategy would be: the privileged values are the ones that you will come to see as superior, once you undergo a change in values. It appears, perhaps, here: "he can see his values as improvements in his own earlier values" (29). Again, however, there is no reason to take the alternate viewpoint as having superior standing. One of Saul's fears, in fact, is that as he gets older he will become a tabloid-reading Fox News watcher and adopt values that he now finds abhorrent.

f) Part and whole.

Richardson summarizes the strategy and its challenges very well here: "For the argument is, after all, an effort to persuade you to value what you as yet don't. So it must rely on some distinction between different parts of you that do and don't value $\mathrm{V}$ or else between different ways you do and don't value it. And this means that the argument still relies on some claimed authority" (66). The strategy is to claim that the privileged values are the ones set by the right part of you, the one with the proper authority. But why should I 
accord any part of me authority, and how would I account for that "should"? Part of Saul, after all, wants him to quit his job and go on tour with his power-pop band, but he pays that part of him no attention. Richardson's answer appeals to "what's most truly oneself" (68), or alternately to "my strongest and most durable aim" (298); part of the idea here is that what is strong and genuine stands in a relationship of command to the rest of oneself. But even if there is a "part" that issues de facto commands, that does not furnish a reason why one should obey them, and there is no particular part of someone that has a privileged claim to represent them more. (Aristotle offers a teleological argument for privileging the rational part, but Nietzsche, I think, gives us no argument about the human function.) Identifying what is "truly my own" is itself an evaluative task that depends on, rather than establishes, a privileged notion of self. This is especially so because "what is truly one's own" is presumably something that is not currently valued if the task is to ground a revision in values.

The fundamental problem with the rubric "You should value V because X values V" (63) is that not even you valuing $\mathrm{V}$ entails that you should value V. Saul, perhaps, just values whatever he happens to value. For the rubric to work not only do we have to locate " $\mathrm{X}$ " on the inside, as it were, we have to tell a background story according to which we are divided into good, should-generating parts that value authoritatively as long as the other parts are appropriately obedient, and regrettable, bad-valuing parts. But then we are far from a naturalistic picture.

To be clear, I am not claiming that Nietzsche does not or cannot endorse and appeal to such values as authenticity, growth, genuineness, self-obedience, and self-awareness in his valuing. I am claiming that appeals to such values do not help explain evaluative privilege or the basis of 'should' claims unless one already takes these values as independently authoritative and acknowledges how they ought to be guiding. I'll return to this issue in Section 5 below.

g) Implicit preference.

This strategy appears here, for example: "Such growth is the criterion by which these value signs are implicitly assessed" (27). The argument thus seems to be a combination of (a) and (c): i.e., we already endorse values according to the meta-value of increased power, so we can identify privileged values as the ones that satisfy this meta-evaluative criterion. In that case, it suffers from the same problems as (a) and (c).

h) Consistency.

Versions of this strategy are expressed using a number of different terms: e.g., in terms of reconciling values (253), preventing values from defeating each other (396), and pulling together and unifying one's parts (399). This example strikes me as the most compelling version: "The values morality itself posits, when accurately applied, judge morality and the moral agent very harshly. Morality 'contradicts itself in certain ways. Different parts of its values contradict one another. Moreover-and this is what Nietzsche most stressesmorality contradicts its own motives..." (260). This functions somewhat differently than the other strategies. Rather than directly arguing for privileged values, it suggests that certain values should be rejected because they generate contradictions; privileged values need to survive a test of consistency. Since the word "contradiction" is used, it even looks 
like a logical test that conveys superior standing to some values (or at least deprives it of others). But this is the problem. It looks like a normative authority can be leveraged to support evaluative privilege. But "contradiction" within the naturalistic framework can only mean that different drives oppose each other. And this presence of conflict is not something that needs to be resolved on pain of inconsistency or incoherence. Saul tries to avoid incoherence, but his values certainly admit lots of conflicts: he values getting more sleep, doing more work, being more social, and so on. And he's fine living with those conflicts. A resolution of the conflicts he feels is not something he values very much at all, or has any reason to.

You could tell Saul: you seem conflicted about what you value, and you should resolve that. And he might even change. But even if he were to change, and come to feel less conflicted (say, by embracing the overwhelming value of getting more sleep), this would be a story of going on in a different way, and not one of recognizing ("accurately") a value that he should affirm.

\section{Internal self-revision}

The idea that we can make sense of what we should value on the basis of what we do value is an appealing one in part because the self-revision of values is so familiar to us. There are a number of familiar scripts to account for how someone might revise their own values in light of the reasons they already have for doing so: one could come to value something when they realize that it provides suitable means to a desired end; one could adopt values that one comes to identify with one's deepest commitments; one could come to adopt the values that one believes one would have if not for some unfortunate psychic obstruction; and so on. These scripts are different from the strategies that Richardson offers, however. Two things set them apart. One, they're rooted in some confidence that at least some of one's values are already authoritative. One revises some values in light of those that are already, unquestionably favored; the evaluative rock-bottom is not whatever one happens to value, but values one recognizes as privileged. Two, within the scripts one cannot really comprehend the relevant changes as rational revisions until they're carried out. Saul, for example, values the environment, but the content of that basic commitment isn't determinate until he extends it to change his consumption and conservation-then we find out what the commitment really means. What he should thereby value does not become apparent until he does value it. These scripts, then, as familiar as they might seem, don't provide a good model for explaining evaluative privilege or constructing it out of what happens to be valued.

At one point Richardson suggests that Nietzsche is aiming at constructing "approximations" (12) of evaluative privilege out of facts about valuing. I'm not sure what an approximation of "should" might be, but I wonder if that's the best that can be hoped for. One possibility is that Nietzsche is just trying to fool himself-and anyone who follows along - into thinking that his own values are privileged, despite the realization that they are not. Another possibility is that this is a roundabout way of asserting that that power is the only and ultimate evaluative authority, while disguising that that is what he is saying. This approximating enterprise could be one of parsing the semantics of realist evaluative discourse or modal discourse. Alternately we could imagine the approximation to be a study of what happens in claiming evaluative privilege: there is the study of what 
goes on in valuing, and there is a more specialized study of what happens when someone claims that someone "should" value.

If Saul is reassessing his whole existence and the first thing he learns is that values are merely valueds and thus there are no true values, there is not much that he can do with that. He can adopt a theoretical attitude toward values and try to identify the causes of human evaluative behavior. But from his own engaged standpoint, the question of what he should value depends on maintaining his commitments to his values-if only to honestly and accurately decide what's important to him in light of his other commitments. The quasi-scientific story does not correct that standpoint; it would obliterate it if there were any real way for him to take it up.

\section{Conclusion}

One can adopt a naturalistic position about values, and one can adopt a position about values in which some have a privileged standing, but the prospects for combining both positions seem dim. Appealing to some middle term to bridge the two sides-whether it be meta-values, or valuing and commanding parts, or something else-does not help because that middle term collapses either into one side or the other. Meta-values are either just valueds or they are inherently privileged; they aren't valueds that convey privilege or authority just by being valued.

One more thing. I think Richardson's Nietzsche would agree that values that are merely studied but not fully endorsed find no equivalent with superficially similar values that are fully endorsed. Here is Richardson's way of framing this, with respect to Nietzsche's value of truthfulness: "And for this we have to feel this kind of life to be worth living. We need to believe we value this life because it's good" (297). V-because-it's-good and disengaged-V aren't the same values with different metaethical standings; they're entirely different ways of valuing. But if that is so, and if evaluative privilege cannot be accounted for, Nietzsche cannot adopt Richardson's naturalism and still hold on to his values. And if he were to drop the naturalism then he would look at different values, too.

\footnotetext{
i John Richardson, Nietzsche's Values, New York: Oxford University Press, 2020. References to this work are given parenthetically by page number in the text.
} 